\title{
STRATEGI PROMOSI E-JOURNAL UNTUK GENERASI-Z DI PERPUSTAKAAN UNIVERSITAS PADJADJARAN
}

\author{
Eko Retno Wulandari*, Edwin Rizal**, \& Elnovani Lusiana** \\ *Perpustakaan FMIPA Universitas Padjadjaran \\ **Program Studi Ilmu Informasi dan Perpustakaan, FIKOM, Universitas Padjadjaran \\ Email: eko@unpad.ac.id,edwin.rizal@unpad.ac.id,elnovanilusiana@gmail.com
}

(Submitted: 14-01-2020, Revised: 31-05-2020, Accepted: 02-06-2020)

DOI: $10.24252 /$ kah.v8i1a1

\begin{abstract}
ABSTRAK: Pemanfaatan e-journal perpustakaan Universitas Padjadjaran belum menunjukkan peningkatan yang signifikan. Perlu dilakukan strategi pemasaran pemanfaatan e-journal untuk meningkatkan antusias penggunanya. Tujuan penelitian ini yaitu untuk mengetahui pemanfaatan e-journal pada generasi Z; media sosial yang digunakan generasi Z; merencanakan strategi promosi e-journal di Perpustakaan Universitas Padjadjaran. Metode penelitian dengan menggunakan metode kuantitatif dengan melakukan survei pada generasi Z sebanyak 120 responden. Berdasarkan penelitian diperoleh bahwa mahasiswa generasi Z menggunakan e-journal untuk menambah pengetahuan, menyelesaikan tugas, pendalaman materi kuliah, dan menulis artikel. Media sosial yang mayoritas digunakan oleh generasi Z adalah Whatsapp, Instagram, dan Youtube. Strategi promosi e-journal perpustakaan Universitas Padjadjaran yaitu mengenal khalayak, target pengguna potensial adalah mahasiswa, menetapkan perilaku yang diharapkan yaitu menggunakan e-journal, menyusun pesan dengan model informatif dan persuatif tentang manfaat e-journal, informasi alamat akses e-journal, jurnal apa saja yang dilanggan, dan cara aksesnya, memilih saluran komunikasi dengan menggunakan media sosial (Youtube, Instagram dan Whatsapp), promosi juga di lakukan di halaman website login masuk Unpad, user education, dan sosialisasi, dan menetapkan anggaran dengan biaya seminimal mungkin.
\end{abstract}

Kata kunci: Promosi perpustakaan; e-journal

\section{STRATEGY OF E-JOURNAL PROMOTION FOR 'Z' GENERATION IN UNIVERSITAS PADJAJARAN}

ABSTRACT: The utilization of e-journal Padjadjaran University library has not shown a significant increase. It is necessary to do a marketing strategy using e-journal to increase the enthusiasm of its users. The purpose of this study is to determine the use of e-journals in Generation $Z$; social media used by generation Z; planning e-journal promotion strategies at the Padjadjaran University Library. The research method using quantitative methods by conducting surveys in generation $Z$ as many as 120 respondents. Based on the research, it was found that $Z$ generation students used e-journals to increase knowledge, complete assignments, deepen lecture material, and write articles. The majority of social media used by Generation $Z$ are Whatsapp, Instagram and Youtube. Padjadjaran University library e-journal promotion strategy is to get to know the audience, target potential users are students, determine the expected behavior that is using ejournals, compile messages with informative and persuasive models about the benefits of $e$ journals, e-journal access address information, what journals are subscribed, and how to access them, choosing communication channels using social media (Youtube, Instagram and Whatsapp), promotions are also carried out on the Unpad login page, user education, and socialization, and and set a budget with minimum cost.

Keywords: Library promotion; e-journal 


\section{PENDAHULUAN}

Teknologi informasi dan internet telah memungkinkan pengguna untuk mengakses informasi dari mana saja. Perkembangan teknologi informasi ini menuntut perpustakaan untuk menyediakan informasi sesuai kebutuhan dan keinginan pengguna. Perpustakaan menghadapi banyak perubahan dan tantangan dengan perkembangan teknologi yaitu, format baru dan berbeda dalam bentuk digital, dan cara-cara baru untuk memberikan informasi dengan berbagai metode pencarian. Tantangan terbesar perpustakaan adalah untuk mengubah semua sumber daya dan jasa dalam format yang user friendly.

Perpustakaan perguruan tinggi dalam perkembangannya menyediakan informasi yang awalnya manual menjadi digital, salah satunya adalah jurnal. Jurnal adalah publikasi ilmiah yang memuat artikel yang ditulis oleh para pakar di bidangnya dan fokus pada disiplin atau bidang studi tertentu, terbit terus menerus dengan judul yang sama, dalam jangka waktu, dan kala terbit yang tertentu pula untuk mendistribusikan temuan penelitian di masa mendatang. Umumnya jurnal yang dimiliki perpustakaan ini ada dua jenis yaitu jurnal tercetak maupun jurnal elektronik (e-journal). Jurnal elektronik menyajikan karya ilmiah dan artikel yang dapat diakses melalui jaringan internet.

Jurnal elektronik bukanlah koleksi yang diberikan secara cuma-cuma oleh pihak universitas, yang mana harus dilanggan kepada sebuah vendor dan memerlukan biaya yang tidak sedikit. Civitas akademika harus memanfaatkan kesempatan ini untuk memanfaatkan $e$-journal yang telah disediakan. Oleh karena itu perlu dilakukan strategi promosi layanan e-journal di perpustakaan Universitas Padjadjaran agar dapat dimanfaatkan civitas akademika semaksimal mungkin. Menurut (Jamaluddin, 2015) pengelola informasi dalam hal ini pengelola perpustakaan perguruan tinggi perlu memikirkan, di antaranya: (a) meningkatkan layanan agar pengguna memanfaatkan e-journal yang dilanggan; (b) perpustakaan melakukan usaha apa saja agar layanan e-journal diketahui oleh pemakai; (c) program kerja apa saja yang dapat dijalankan untuk mempertemukan layanan yang ada dengan kebiasaan pencarian informasi pemakai.

Walaupun perpustakaan memiliki sumber informasi dan pengetahuan yang berlimpah, bisa jadi pengguna tidak menyadari sumber-sumber informasi yang ada di perpustakaan. Perpustakaan perlu menemukan cara seefektif mungkin untuk mempromosikan jurnal elektronik yang dilanggan sehingga dapat menarik pengguna, dan meningkatkan kesadaran akan tersedianya jurnal elektonik. Perpustakaan perguruan tinggi perlu melakukan usaha agar layanan e-journal diketahui, dan dimanfaatkan civitas akademika. Tujuan dasar promosi dan pemasaran layanan perpustakaan adalah untuk mencapai kepuasan pengguna, menjamin kelangsungan hidup lembaga, dan meningkatkan nilai yang dirasakan dari layanan- Perpustakaan dapat mempromosikan penggunaan layanan dan sumber-sumber daya yang ada tetapi tidak dapat membuat keuntungan dari promosi yang dilakukan karena perpustakaan adalah lembaga non profit (Patil \& Pradhan, 2014).

Pemasaran bagi perpustakaan adalah bagaimana mengidentifikasi kebutuhan pengguna, membantu pengguna memenuhi kebutuhan informasi, dan bagaimana perpustakaan dapat memberikan layanan yang sesuai. Bauran pemasaran mengacu pada satu set variabel yang dapat digunakan oleh perpustakaan untuk mempromosikan layanan dan sumber daya untuk pengguna. Bauran pemasaran secara tradisional disebut sebagai 5P: Price (harga), Product (produk), Promotion (promosi), Place (tempat), dan People (orang). Meskipun bauran pemasaran dikembangkan untuk menyampaikan keuntungan dari produk yang nyata, dengan fokus pada pemasaran produk, para ahli setuju tentang pentingnya menerapkan fokus ini untuk promosi layanan (Malekani \& Benard, 2018). Promosi telah berkembang dan sekarang lebih luas bukan hanya produk, tetapi juga mencakup layanan. Salah satu strategi bauran pemasaran utama adalah promosi yang efektif.

Promosi adalah salah satu komponen penting yang dibutuhkan oleh lembaga nirlaba seperti perpustakaan. Promosi digunakan untuk menginformasikan mengenai produk dan membujuk 
para konsumen di pasar sasaran sebuah perusahaan dengan memberikan informasi yang bersifat terbuka agar khalayak menjadi tahu mengenai apa yang dihasilkan atau ditawarkan oleh lembaga ke pasarnya, dengan sifatnya yang terbuka. Promosi yang dilakukan harus sesuai dengan visi dan misi organisasi, dimana investasi yang dikeluarkan organisasi sebanding dengan manfaat yang diperoleh dari kegiatan promosi yang dijalankan. Manfaat promosi layanan perpustakaan adalah peningkatan penggunaan, peningkatan nilai dalam organisasi, pendidikan pengguna dan perubahan persepsi. Tujuan promosi (Tjiptono, 2008) adalah memberikan informasi tentang produk yang ditawarkan, mendorong dan mempengaruhi pengguna untuk memanfaatkan dan menggunakan produk, serta memberikan kesadaran pada pengguna akan manfaat yang ditawarkan.

Menurut (Kotler, 2009) alat bauran promosi antara lain: iklan (advertising), promosi penjualan (sales promotion), hubungan masyarakat dan publisitas (public relation \& publicity), acara khusus dan pengalaman (event and experiences), pemasaran langsung (direct and interactive marketing), word-of-mount marketing, dan penjualan pribadi (personal selling). Pemasaran tidak hanya tentang mengembangkan dan mempromosikan layanan dan produk baru tetapi juga tentang membawa kesadaran kepada klien tentang layanan dan produk yang ada. Dalam penelitian ini penulis fokus pada strategi promosi e-journal yang ada di perpustakaan Universitas Padjadjaran. Dalam penelitian ini penggunaan alat bauran promosi ditekankan pada publikasi $e$ journal menggunakan media baru yang digunakan oleh generasi Z. Survei dilakukan untuk mengetahui media sosial yang banyak digunakan generasi $\mathrm{Z}$ yang akan digunakan sebagai media dalam strategi promosi e-journal Perpustakaan Universitas Padjadjaran. Strategi pemasaran pemanfaatan $e$-journal perlu dilakukan untuk meningkatkan antusias pengguna menggunakan $e$ journal.

Strategi promosi dalam mengembangkan komunikasi yang efektif menurut (Kotler, 2009): (a) Mengidentifikasi target audiens. Lembaga harus dapat beradaptasi dengan kebutuhan, keinginan, dan nilai audiens target mereka. Lembaga dapat memilih kelompok mana yang ingin mereka targetkan; (b) Menentukan tujuan komunikasi. Pemasar dapat mencari respon kognitif, afektif, atau perilaku dari audiens sasaran sehingga mengubah persepsi konsumen dan membuat konsumen melakukan tindakan untuk menggunakan produk yang dipasarkan.; (c) Merancang pesan. Pesan yang disampaikan harus persuatif; (d) Memilih saluran komunikasi. Dalam menarik minat konsumen, saluran komunikasi disesuaikan dengan keinginan pasar; (e) Menetapkan total anggaran promosi.

Penelitian ini dilakukan kepada generasi Z karena pengguna perpustakaan masa sekarang adalah generasi Z. Generasi Z adalah kelompok individu yang lahir dengan rentang tahun antara 1995 sampai 2010 (Oblinger \& Oblinger, 2005). Generasi Z juga dapat didefinisikan sebagai orang yang lahir antara tahun 1995 sampai tahun 2012, dan tumbuh di era teknologi informasi, memiliki kekuatan dalam mempengaruhi perputaran ekonomi dunia, pengguna situs jejaring sosial yang paling kritis serta aktif terlibat dalam pertukaran informasi dan percakapan online (Kitchen \& Proctor, 2015); aktif dalam interaksi sosial didunia maya melalui jejaring sosial dan lebih menyukai petunjuk visual dibandingkan dengan teks (Palfrey \& Gasser, 2008). Secara umum, generasi Z memiliki ciri-ciri karakteristik seperti kemampuan digital yang lebih baik, ingin selalu terhubung dengan dunia melalui internet, berpikiran terbuka, menyukai kampanye kreatif yang kekinian, menghendaki perubahan sosial, sanggup berkompromi dan bekerja tim, familiar, dan intens dengan teknologi informasi. Generasi $\mathrm{Z}$ juga suka dengan kecepatan baik dalam respon yang diharapkan maupun kecepatan dalam memperoleh informasi, cepat berpindah dari satu aktifitas ke aktifitas lain dan aktifitas tersebut dapat mereka lakukan secara bersamaan (multi tasking). Karena ada beberapa karakteristik generasi $\mathrm{Z}$ yang berbeda dari generasi sebelumnya maka sebelum melakukan promosi, perpustakaan Universitas Padjadjaran sebaiknya melakukan survei terlebih dahulu. 


\section{METODOLOGI PENELITIAN}

Penelitian kuantitatif adalah pendekatan penelitian yang banyak dituntut menggunakan angka, mulai dari pengumpulan data, penafsiran terhadap data, serta penampilan hasilnya (Arikunto, 2014). Metode penelitian survei yang digunakan dalam penelitian ini, yakni metode survei deksriptif. Metode survei deskriptif ialah untuk mengukur dengan cermat fenomena sosial tertentu (Singarimbun, 2012). Menurutnya, peneliti mengembangkan konsep serta menghimpun fakta-fakta akan tetapi, tidak menguji hipotesis. Peneliti akan mendeskripsikan secara kuantitatif perilaku atau opini-opini dari suatu populasi dengan meneliti sampel populasi tersebut. Dari sampel ini, maka penelitian ini bertujuan untuk melakukan generalisasi. Ciri khas penelitian survei adalah penelitian yang datanya dikumpulkan dari sampel atas populasi untuk mewakili seluruh populasi dan menggunakan kuesioner. Metode penelitian survei dalam penelitian ini ialah untuk mengetahui pemanfaatan e-journal dan media sosial yang digunakan oleh generasi $\mathrm{Z}$. Subjek penelitian ini adalah mahasiswa Universitas Padjadjaran. Teknik pengumpulan data dilakukan dengan penyebaran kuesioner, observasi, dan studi pustaka. Pengumpulan data dilakukan dengan dengan random sampling menggunakan survei kepada 120 generasi Z mahasiswa Universitas Padjadjaran. Penelitian dilakukan di bulan Juni-Oktober 2019.

\section{HASIL DAN PEMBAHASAN}

Penelitian ini dilakukan dengan melakukan survei kepada mahasiswa generasi Z. Peneliti melakukan survei kepada 120 mahasiswa Universitas Padjadjaran yang merupakan generasi Z tentang pemanfaatan e-journal, dan media sosial yang digunakan mahasiswa dengan komposisi laki-laki sebanyak 27\% (33 orang) dan perempuan 73\% (87 orang). Berikut hasilnya:

Tabel 1. Pemanfaatkan Jurnal dalam Bentuk Cetak atau Elektronik

\begin{tabular}{clcc}
\hline No & \multicolumn{1}{c}{ Kategori Jawaban } & $\mathrm{f}$ & $\%$ \\
\hline 1 & Jurnal elektronik & 114 & 95 \\
2 & $\begin{array}{l}\text { Jurnal elektronik \& } \\
\text { Tercetak }\end{array}$ & 6 & 5 \\
3 & 0 & 0 \\
& \begin{tabular}{l} 
Jurnal tercetak \\
\multicolumn{1}{c}{ Jumlah }
\end{tabular} & 120 & 100 \\
\hline \multicolumn{2}{l}{ Sumber: Hasil pengolahan data, 2019 }
\end{tabular}

Terdapat peralihan penggunaan sumber informasi mahasiswa generasi $\mathrm{Z}$ yaitu lebih banyak mengakses jurnal elektronik dibandingkan jurnal tercetak. Pernyataan di atas diperkuat oleh penelitian (Azwar \& Amalia, 2017) bahwa jurnal elektronik sebagai bahan referensi mempunyai tingkat pemanfaatan yang relatif tinggi. Pemanfaatan jurnal elektronik ini sebagian besar dimanfaatkan dalam penulisan skripsi dan sebagai referensi. Civitas akademika lebih senang untuk mengakses e-journal karena memberikan akses yang cepat, dapat diakses di mana saja dan kapan saja, dan dapat memiliki jurnal elektronik tersebut dengan mengunduhnya. 


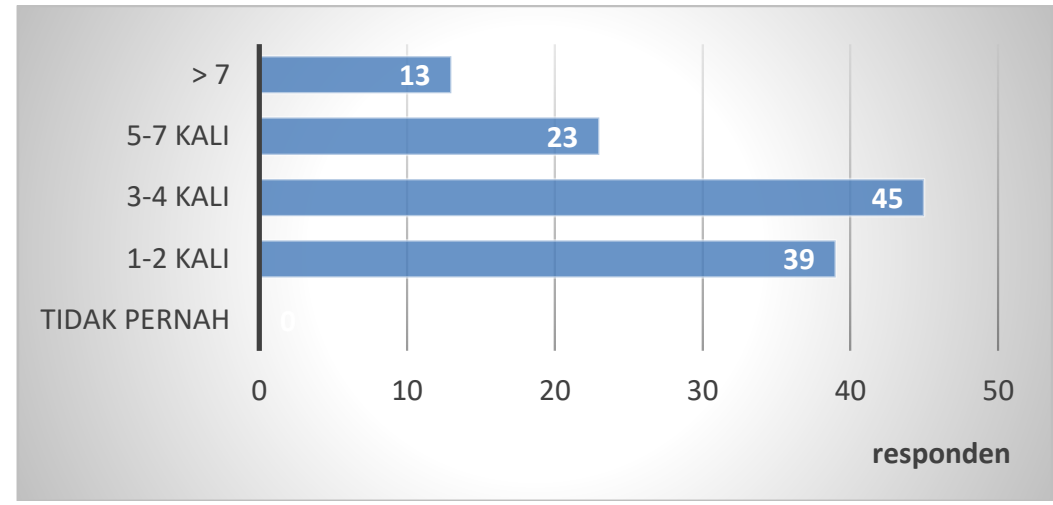

Gambar 1. Mahasiswa mengakses e-journal dalam seminggu

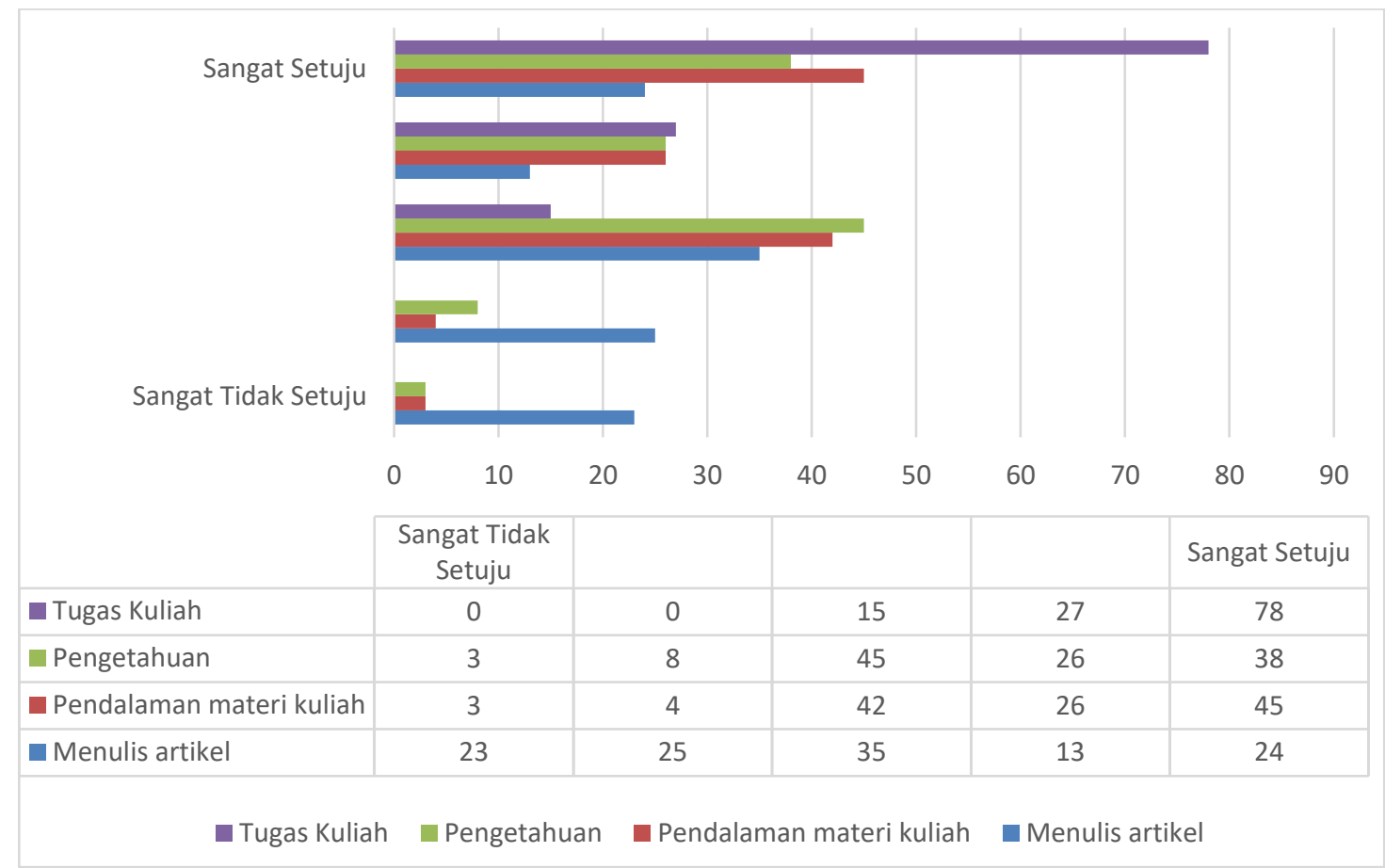

Gambar 2. Tujuan mahasiswa memanfaatkan jurnal elektronik

Dari hasil penelitian diperoleh bahwa mahasiswa generasi Z sangat jarang memperoleh jurnal elektronik dari website Kandaga. Mahasiswa lebih sering mendapatkan jurnal elektronik dari search engine. Oleh karena itu diperlukan strategi promosi agar mahasiswa mau memanfaatkan fasilitas jurnal elektronik website Kandaga. Menurut (Bhardwaj \& Jain, 2016), akses terbuka dan mesin pencari (search engine) telah menciptakan tantangan baru dan pada saat yang sama membuka batas baru untuk memberikan layanan kepada pengguna. Oleh karena itu, mempromosikan dan memasarkan sumber daya yang ada menjadi hal penting bagi perpustakaan. 


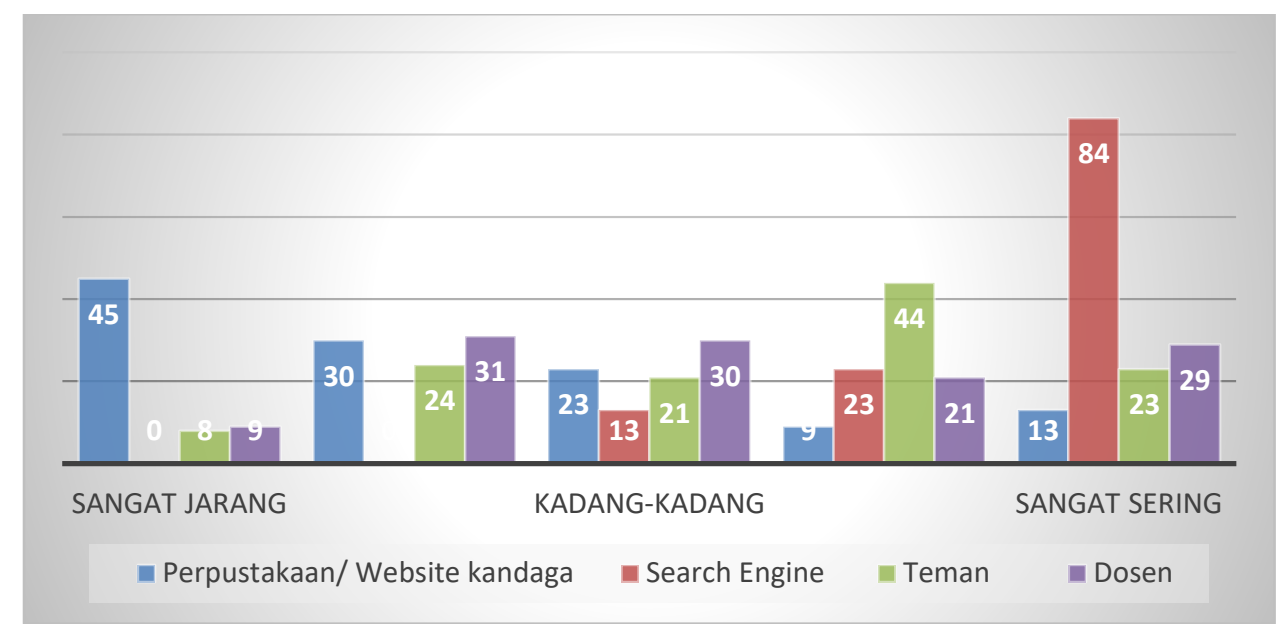

Gambar 3. Sumber responden memperoleh jurnal elektronik

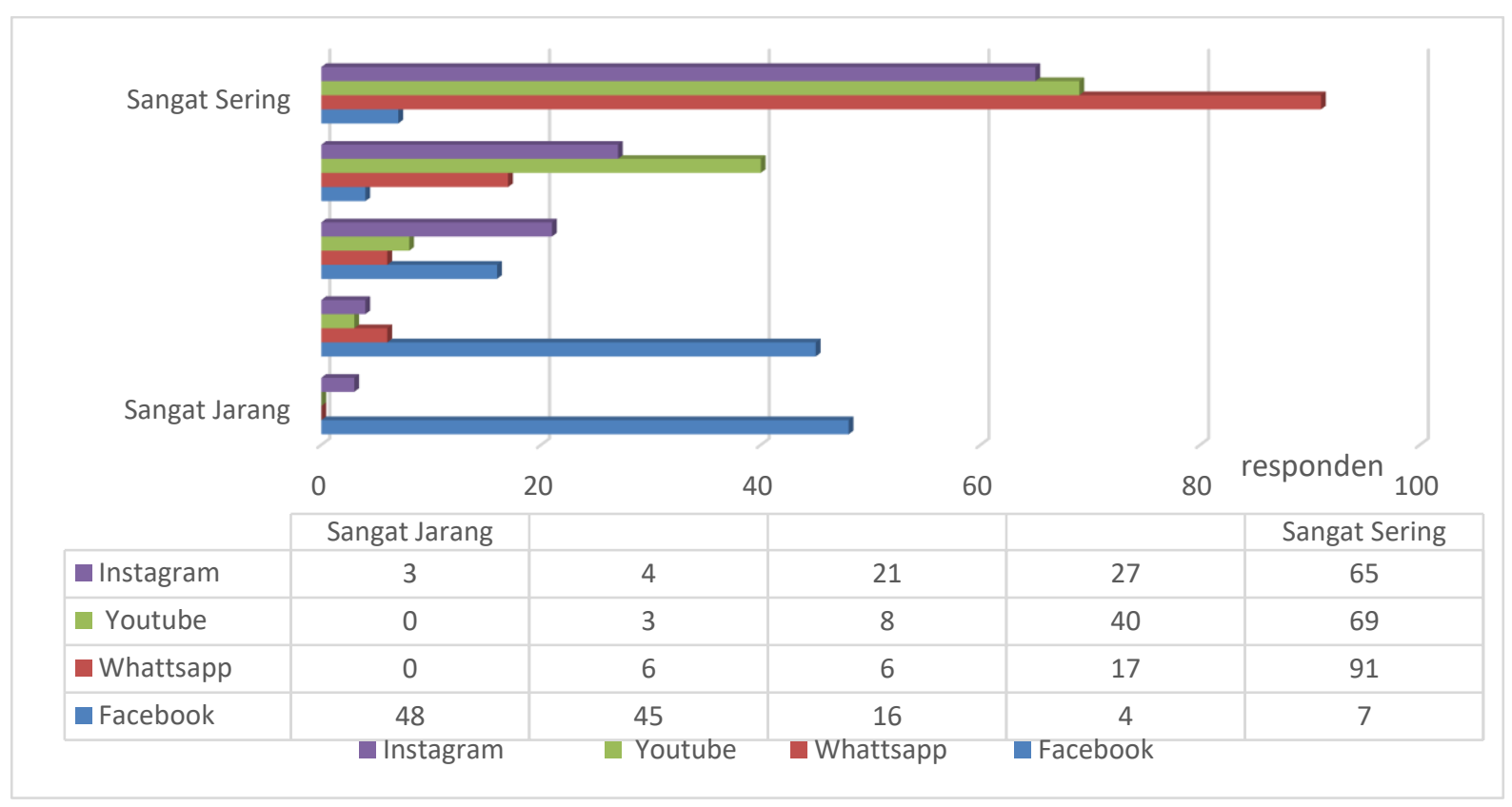

Gambar 4. Media sosial yang digunakan responden

Dari data tersebut diperoleh bahwa mahasiswa generasi Z sudah sangat jarang menggunakan media sosial Facebook, dan sangat sering menggunakan media sosial Whatsapp, Youtube dan Instagram. Promosi jurnal elektronik perpustakaan Universitas Padjadjaran dapat dilakukan dengan menggunakan media sosial yang banyak digunakan mahasiswa yaitu Whatsapp, Youtube dan Instagram. Menurut (Yi, 2016) penggunaan YouTube sebagai media promosi berhasil untuk memasarkan koleksi perpustakaan. Ericsson mencatat hingga 2016 sekitar 20\% remaja berusia 16-19 menonton video melalui Youtube. Rata-rata remaja sekitar tiga jam menghabiskan waktu mereka di depan layar perangkat mobile (Ester, 2016). Instagram merupakan media sosial online yang bisa menjadi salah satu alat yang efektif mempromosikan kegiatan dan layanan perpustakaan. Hal ini didukung oleh pernyataan (Azwar \& Sulthonah, 2018) bahwa Instagram dengan banyak keuntungan dari fitur-fiturnya, terbukti ampuh dalam kegiatan promosi, berbagi informasi dan memberikan dampak yang positif bagi perpustakaan. Pemanfaatan Instagram sebagai media promosi di perpustakaan perlu dilakukan secara terus menerus, format yang diupload pada Instagram sebaiknya seimbang antara foto dan video. Kemudian, video yang diunggah harus dibuat dan diedit sebaik mungkin untuk mendapatkan lebih banyak pengikut, 
diharapkan bahwa perpustakaan memanfaatkan hastags populer di Instagram, sehingga lebih banyak orang akan melihat postingan dan akan ada lebih banyak orang yang akan tertarik mengikuti Instagram perpustakaan.

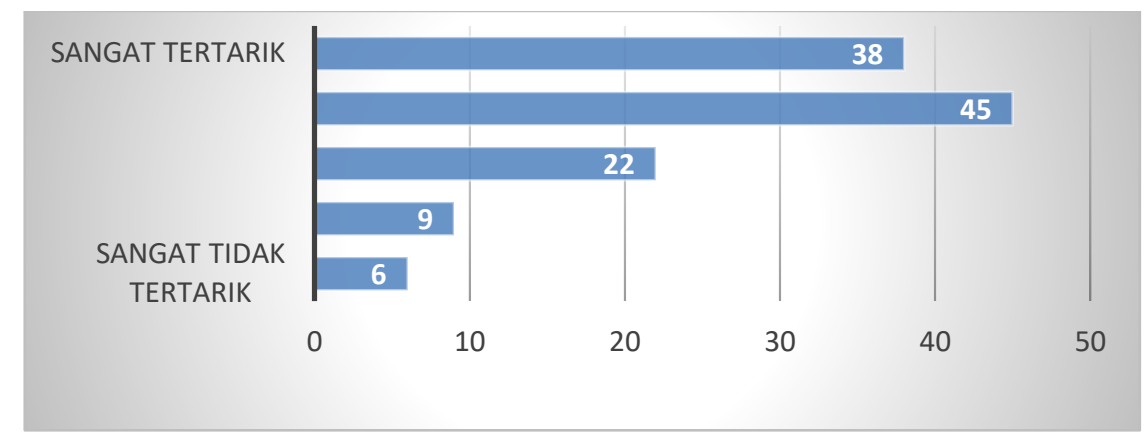

Gambar 5. Kesediaan mengikuti sosialisasi e-journal yang diadakan perpustakaan Universitas Padjadjaran

\section{Strategi Promosi E-Journal Perpustakaan Universitas Padjadjaran Identifikasi Target}

Pengidentifikasian target konsumen adalah langkah awal yang dibutuhkan dalam perencanaan dan pengembangan strategi promosi. Dari hasil survei diperoleh bahwa mahasiswa generasi $\mathrm{Z}$ memanfaatkan jurnal untuk menambah pengetahuan, menyelesaikan tugas, pendalaman materi kuliah, dan menulis artikel. Mahasiswa generasi Z Universitas Padjadjaran menggunakan jurnal elektronik, mencari referensi dari jurnal elektronik, dan mengakses beberapa kali setiap minggunya. Oleh karena itu ditetapkan sasaran utama promosi e-journal Perpustakaan Universitas Padjadjaran adalah mahasiswa.

\section{Penentuan Tujuan Promosi}

Kegiatan promosi tidak terlepas dari kegiatan komunikasi. Seperti apa yang telah diungkapkan (Kotler \& Kelller, 2009), bahwa promosi merupakan kegiatan yang mengkomunikasikan kelebihan produk serta membujuk pengguna potensial untuk membelinya. Tujuan promosi e-journal adalah (1) menginformasikan, dapat berupa menginformasikan keberadaaan e-journal yang tersedia, memperkenalkan cara penggunaan, cara memperoleh $e$ journal, dan membangun citra perpustakaan Universitas Padjadjaran; (2) membujuk pengguna untuk mengubah persepsi pengguna, mendorong untuk menggunakan e-journal perpustakaan Universitas Padjadjaran; dan mengingatkan berupa menjaga ingatan dan membuat pengguna ingat akan keberadaan e-journal di perpustakaan Universitas Padjadjaran. Dengan dilakukannya promosi e-journal berharap ada respon positif untuk mempengaruhi perilaku mahasiswa sehingga mahasiswa menggunakan jurnal elektronik yang dilanggan. Pengguna menjadi tahu koleksi e-journal yang ada dan tersedia di perpustakaan, bagi pengguna yang belum pernah memanfaatkan akan mengenal dan tertarik untuk memanfaatkan jurnal elektronik. Promosi dianggap berhasil jika produk e-journal yang mengakses meningkat dari waktu ke waktu.

\section{Perancangan Pesan}

Lembaga merancang pesan yang akan disampaikan sehingga menarik minat dan perhatian pengguna. Isi pesan mencakup bagaimana mengatakannya secara simbolis (format pesan), apa yang dikatakan (isi pesan), siapa yang seharusnya mengatakannya (sumber pesan), bagaimana mengatakannya secara logis (struktur pesan). Pesan harus dirancang sedemikian menarik agar masyarakat terutama pengguna sasaran mengetahui keberadaan produk di pasaran. Sebuah pesan promosi sebaiknya lugas, sederhana, dan mudah dimengerti. Isi pesan promosi e-journal 
dapat menggunakan tagline yaitu slogan yang dibuat yang mengungkapkan betapa pentingnya manfaat e-journal yang dilanggan perpustakaan. Isi pesan promosi juga berisi alamat akses jurnal elektronik, informasi jurnal elektronik apa saja yang dilanggan Perpustakaan Universitas Padjadjaran, dan cara akses jurnal elektronik, dan informasi bahwa website Kandaga menyediakan jurnal elektronik yang bisa diakses secara gratis oleh mahasiswa.

\section{Pemilihan Saluran Komunikasi}

Strategi promosi yang keempat adalah pemilihan saluran komunikasi. Saluran komunikasi promosi e-journal menggunakan Whatsapp, Instagram, dan Youtube. Sedangkan promosi melalui Facebook tidak dilakukan karena mahasiswa generasi $\mathrm{Z}$ sudah sangat jarang menggunakan media Facebook. Promosi dengan Whattshap menggunakan pesan-pesan yang kemudian dikirim secara berkala ke grup-grup mahasiswa. Promosi melalui Whatsapp juga memberikan informasi tentang Youtube dan Instagram yang digunakan untuk mempromosikan e-journal yang tersedia dan dilanggan. Promosi menggunakan Instagram, dan Youtube berisi alamat akses jurnal elektronik, informasi jurnal elektonik yang dilanggan Perpustakaan Universitas Padjadjaran, dan video tutorial singkat cara akses jurnal elektronik. Video tentang promosi e-journal di Youtube disimpan di beranda halaman depan website Kandaga, dan diputar saat penerimaan mahasiswa baru.

Sedangkan promosi juga dilakukan menggunakan halaman depan website saat masuk login Unpad karena hampir semua civitas akademika menggunakan login Unpad yaitu saat masuk ke unpad.ac.id. Promosi ini memberi informasi bahwa jurnal elektronik merupakan layanan unggulan Perpustakaan Universitas Padjadjaran. Hal ini seperti penelitian (Bhardwaj \& Jain, 2016) bahwa perpustakaan harus menerapkan tekonologi terbaru dalam mempromosikan sumber daya dan layanan sehingga sumber informasi yang ada di perpustakaan dapat dimanfaatkan secara optimal. Promosi melalui website dapat meningkatkan visibilitas perpustakaan sumberdaya elektronik, bahkan untuk jangka waktu yang relatif singkat, dapat membantu mencapai peningkatan yang diinginkan dalam penggunaan. Perpustakaan Universitas Padjadjaran juga melakukan kegiatan user education (pendidikan pemakai perpustakaan) bagi mahasiswa baru dan mengadakan kegiatan sosialisasi e-journal yang dilanggan secara berkelanjutan.

\section{Penetapan Total Anggaran Promosi}

Setelah pemilihan saluran komunikasi, perpustakaan menetapkan total anggaran yang diperlukan untuk promosi. Penggunaan media sosial sebagai saluran promosi sangat efisien dan hemat dalam segi biaya hingga nol rupiah. Konten-konten yang akan dibuat bisa dilakukan oleh pustakawan sendiri, sedangkan konten video dapat dibuat dengan kerjasama antara pustakawan dan bagian IT universitas. Anggaran promosi yang menggunakan biaya minim ini diperkuat oleh (Bhardwaj \& Jain, 2016) bahwa perpustakaan di negara-negara berkembang menggunakan teknologi terbaru seperti Web 2.0 dan layanan seluler untuk melakukan pemasaran dengan cara yang efisien dan hemat biaya untuk memasarkan sumber daya dan layanan mereka.

Setelah melakukan promosi e-journal yang dilanggan Perpustakaan Universitas Padjadjaran perlu lagi dilakukan evaluasi untuk mengetahui pencapaian promosi yang telah dilakukan, dan target apa saja yang belum dicapai. Evaluasi untuk melakukan perbaikan-perbaikan agar promosi e-journal yang dilakukan efektif dan efisien, serta tujuan utama promosi tercapai yaitu mahasiswa memanfaatkan, dan menggunakan e-journal yang dilanggan Perpustakaan Universitas Padjadjaran. Evaluasi promosi e-journal dilakukan dengan melihat dari penetapan tujuan promosi, jika tujuan tercapai maka dapat dikatakan bahwa promosi e-journal berhasil. Promosi perpustakaan harus terus dilakukan secara kontinyu, masuk pada program kerja perpustakaan. Layanan e-journal juga harus ditingkatkan dengan akses yang cepat, penelusuran yang mudah, dan penyediaan sumber informasi yang sesuai dengan kebutuhan civitas akademika. Evaluasi dan monitoring perlu dilakukan setelah promosi e-journal dilakukan untuk mengetahui pencapaian promosi yang telah dilakukan, dan target apa saja yang belum dicapai 
Berdasarkan strategi promosi diatas diperoleh model strategi promosi e-journal Perpustakaan Universitas Padjadajran sebagai berikut:

Strategi Dalam Mempromosikan E-Journal Yang Dilanggan Perpustakaan Universitas Padjadjaran

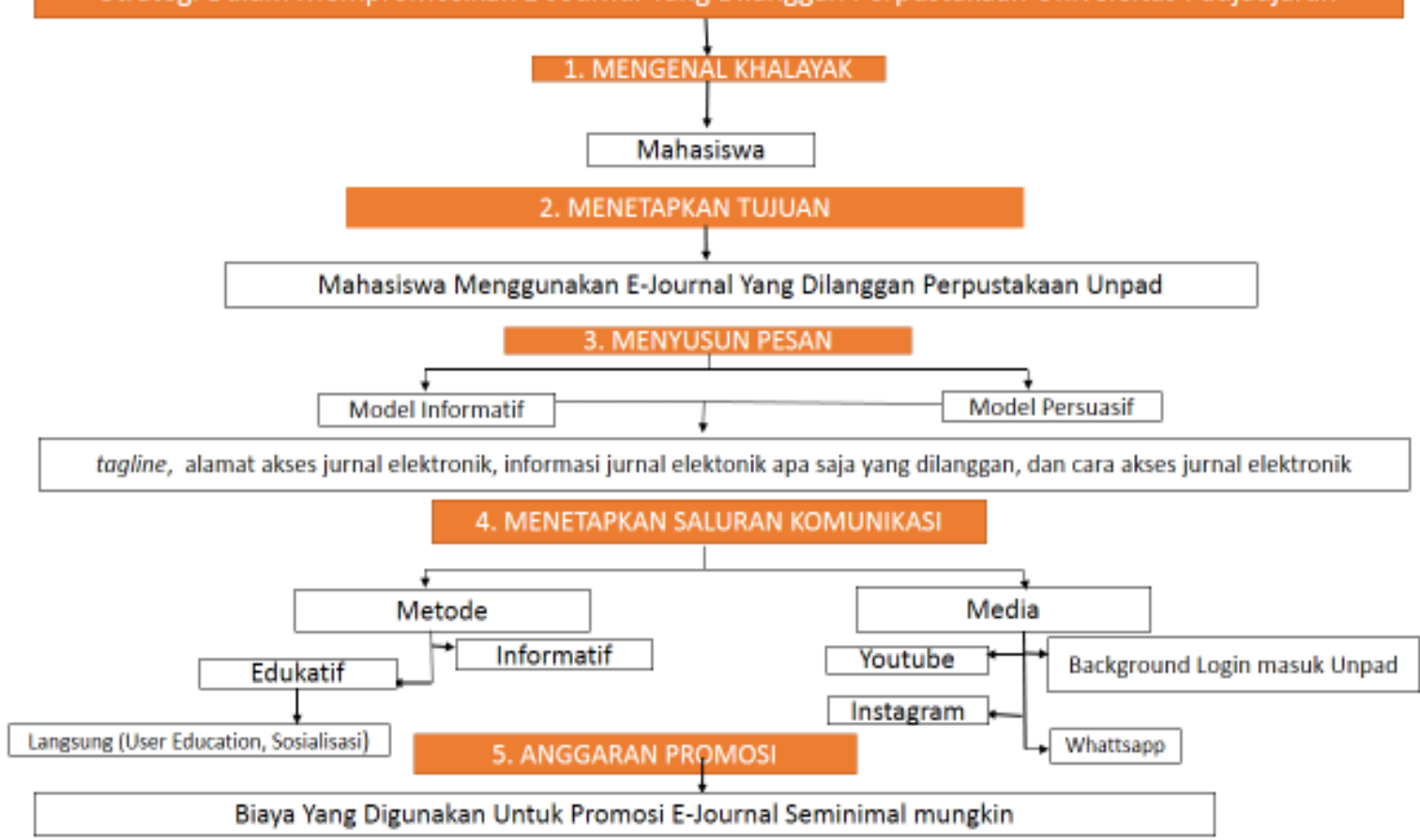

Gambar 6. Strategi promosi e-journal yang dilanggan Perpustakaan Universitas Padjadjaran

\section{KESIMPULAN}

Sebagian besar mahasiswa generasi Z telah menggunakan e-journal sebagai sumber referensi, dan memanfaatkannya untuk menambah pengetahuan, menyelesaikan tugas, pendalaman materi kuliah, dan menulis artikel. Media sosial yang mayoritas digunakan oleh mahasiswa generasi Z di Universitas Padjadjaran adalah Whatsapp, Youtube dan Instagram. Media sosial yang banyak digunakan mahasiswa generasi Z ini akan digunakan sebagai media dalam mempromosikan $e$ journal yang dilanggan perpustakaan Universitas Padjadjaran. Strategi perpustakaan Universitas Padjadjaran dalam mempromosikan e-journal yang dilanggan dengan (1) mengenal khalayak, target pengguna potensial e-journal adalah mahasiswa; (2) menetapkan perilaku yang diharapkan yaitu menggunakan e-journal yang dilanggan Perpustakaan Universitas Padjadjaran yaitu memanfaatkan dan menggunakan e-journal yang dilanggan perpustakaan; (3) menyusun pesan dengan model informatif dan model persuasif dengan menggunakan tagline yaitu slogan yang dibuat dalam bentuk visual maupun verbal yang mengungkapkan betapa pentingnya manfaat $e$ journal yang dilanggan perpustakaan. Isi pesan promosi juga mencakup informasi alamat akses jurnal elektronik, informasi jurnal elektonik apa saja yang dilanggan, dan cara akses jurnal elektronik; (4) memilih saluran komunikasi, metode informatif dan menggunakan media (Youtube, Instagram dan Whatsapp), pesan promosi juga di lakukan di halaman website login masuk Unpad, dan promosi langsung melalui user education dan kegiatan sosialisasi; (5) menetapkan anggaran. Berdasarkan saluran promosi yang dipilih, anggaran promosi $e$-journal bisa dilakukan biaya yang rendah bahkan free/ bebas biaya.

\section{DAFTAR PUSTAKA}

Arikunto, S. (2014). Prosedur Penelitian: Suatu Pendekatan Praktik. Jakarta: Rineka Cipta.

Azwar, M., \& Amalia, R. (2017). Pemanfaatan Jurnal Elektronik Sebagai Sumber Referensi Dalam 
Penulisan Skripsi Di Institut Pertanian Bogor. LIBRARIA: Jurnal Perpustakaan, 5(1), 87. https://doi.org/10.21043/libraria.v5i1.2311

Azwar, M., \& Sulthonah, S. (2018). The Utilization of Instagram as a Media Promotion : The Case Study of Library in Indonesia. Insaniyat: Journal of Islam and Humanities, 2(2), 147-159. https://doi.org/10.15408/insaniyat.v2i2.7320

Bhardwaj, R. K., \& Jain, P. K. (2016). Marketing of Library Resources and Services: A structured Literature Review. DESIDOC Journal of Library and Information Technology, 36(3), 119125. https://doi.org/10.14429/djlit.36.3.10027

Conley, T., \& Tucker. (2005). Matching Media to Audience Equals Marketing Success. College \& Undergraduate Libraries 12:47-64.

Duke, L. M., \& Tucker, T. (2007). How to Develop a Marketing Plan for an Academic Library. Technical Services Quarterly 25:51-68.

Ester. (2016). Mengenal Generasi Millennial. Retrieved from https://www.kominfo.go.id/content/detail/8566/mengenal-generasi-

millennial/0/sorotan_media

Jamaluddin. (2015). Mengenal Elektronik Jurnal Dan Manfaatnya Bagi Pengembangan Karier Pustakawan. JUPITER, XIV(2), 38-44.

Kitchen, \& Proctor. (2015). Marketing Communications in A Postmodern World. Journal of Business Strategy, 36(5): 34-42.

Kotler, P. (2009). Manajemen Pemasaran. Jakarta: Erlangga.

Kotler, \& Kelller, K. L. (2009). Manajemen Pemasaran Jilid 1 edisi 12. Jakarta: Erlangga.

Malekani, A., \& Benard, R. (2018). Effective Outreach Techniques for The Promotion of Library Information Resources in Academic Libraries in Tanzania: A case of Sokoine National Agricultural Library. Library Philosophy and Practice, 2018(February).

Oblinger, D., \& Oblinger, J. (2005). Educating the NetGen. Washington: Educause.

Palfrey, \& Gasser. (2008). Born Digital: Understanding the First Generation of Digital Natives. New York: Basic Books.

Patil, S. K., \& Pradhan, P. (2014). Library Promotion Practices and Marketing of Library Services: A Role of Library Professionals. Procedia - Social and Behavioral Sciences, 133, 249-254. https://doi.org/10.1016/j.sbspro.2014.04.191

Putra, Y. S. (2016). Teori Perbedaan Generasi. Among Makarti, Vol 9 No18.

Singarimbun, M. (2012). Metode Penelitian Survai. Jakarta: LP3ES.

Smith, D. A. (2011). Strategic Marketing of Library Resources and Services. College and Undergraduate Libraries, 18(4), 333-349. https://doi.org/10.1080/10691316.2011.624937

Tjiptono, F. (2008). Strategi Pemasaran. Yogyakarta: Andi Offset.

Yi, Z. (2016). Effective Techniques for The Promotion of Library Services and Resources. Information Research, 21(1) 